\title{
Producción de sentidos subjetivos y prácticas burocráticas: análisis de la película La vida de los otros
}

Omar Alejandro Bravo*

Doctor en Psicología, Universidad de Brasilia. Profesor, Facultad de Derecho y Ciencias Humanas, Universidad Icesi, Cali, Colombia.

Correo electrónico: oabravo@icesi.edu.co

Recibido: 25 de agosto del 2015

Aprobado: 12 de noviembre del 2015

Cómo citar este artículo: Bravo, 0. A. (2015). Producción de sentidos subjetivos y prácticas burocráticas: Análisis de la película La vida de los otros. Pensando Psicología, 11(18), 185-193. doi: http://dx.doi. org/10.16925/pe.v11i18.1228

\section{Resumen}

Propósito: abordar la cuestión de la burocracia, sus efectos subjetivos y su relación funcional y estructural con determinadas prácticas sociales e institucionales, tema en general tratado de forma fragmentada desde diferentes áreas de conocimiento. Tema: el análisis de la película $L a$ vida de los otros permite realizar una lectura que vincule este fenómeno con formas de producción de tipos particulares de subjetividad, caracterizadas fundamentalmente por su alienación con relación a las consecuencias y alcances de su praxis. Al mismo tiempo, es posible reflexionar sobre las formas en que las propias prácticas de los sujetos permiten nuevos espacios de producción de sentidos subjetivos. Desarrollo: las nociones de sentido subjetivo, subjetividad y subjetividad social desarrolladas por Fernando González Rey constituyen operadores teóricos que permiten esta construcción interpretativa, tomando en consideración para este análisis las interacciones sucedidas entre los protagonistas de la película. Conclusiones: el análisis de la película muestra los condicionamientos sociales e individuales para la producción de nuevos sentidos subjetivos por parte de los protagonistas, así como permite reflexionar sobre la relación entre prácticas institucionales burocráticas y formas de producción de subjetividad.

Palabras clave: burocracia, sentidos subjetivos, subjetividad. 


\title{
Production of Subjective Meanings and Bureaucratic Practices: Analysis of the Film La vida de los otros
}

\begin{abstract}
Purpose: to address the question of bureaucracy, its subjective effects and its functional and structural relationship with certain social and institutional practices, a topic which is generally addressed in a fragmented manner from different areas of knowledge. Topic: The analysis of the film La vida de los otros facilitates an interpretation that links this phenomenon with forms of production of particular types of subjectivity, fundamentally characterized by their alienation in terms of the consequences and scopes of their praxis. At the same time, it is possible to reflect upon the ways in which the practices of the subjects themselves facilitate new venues for the production of subjective meanings. Development: The notions of subjective meaning, subjectivity and social subjectivity developed by Fernando González Rey constitute technical operators that facilitate this interpretive construction, take into consideration the interactions that occur among the protagonist of the film for this analysis. Conclusions: The analysis of the film shows the social and individual conditions for the production of new subjective meanings by the protagonists, while also facilitating reflection on the relationship between bureaucratic institutional practices and the forms of production of subjectivity.
\end{abstract}

Keywords: bureaucracy, subjective meanings, subjectivity.

\section{Produção de sentidos subjetivos e práticas burocráticas: análise do filme $A$ vida dos outros}

\section{Resumo}

Propósito: abordar a questão da burocracia, seus efeitos subjetivos e sua relação funcional e estrutural com determinadas práticas sociais e institucionais, tema em geral tratado de forma fragmentada de diferentes áreas do conhecimento. Tema: a análise do filme $A$ vida dos outros permite realizar uma leitura que vincula esse fenômeno com formas de produção de tipos particulares de subjetividade, caracterizados fundamentalmente por sua alienação a respeito das consequências e alcances de sua práxis. Ao mesmo tempo, é possível refletir sobre as formas nas quais as próprias práticas dos sujeitos permitem novos espaços de produção de sentidos subjetivos. Desenvolvimento: as noções de sentido subjetivo, subjetividade e subjetividade social desenvolvidas por Fernando González Rey constituem operadores teóricos que possibilitam essa construção interpretativa, considerando para esta análise as interações acontecidas entre os protagonistas do filme. Conclusões: a análise do filme mostra os condicionamentos sociais e individuais para a produção de novos sentidos subjetivos por parte dos protagonistas, bem como proporciona refletir sobre a relação entre práticas institucionais burocráticas e formas de produção de subjetividade.

Palavras-chave: burocracia, sentidos subjetivos, subjetividade. 


\section{Algunas consideraciones en torno al fenómeno burocrático}

El problema de la burocracia aparece como tal con el comienzo de la época moderna y la organización cada vez más compleja del Estado, en función principalmente de las nuevas formas de control social que el capitalismo naciente precisaba establecer.

En líneas generales, es posible concebir dos grandes maneras de interpretar el fenómeno de la burocracia: la que le otorga una función positiva, en términos de la necesidad y posibilidad de una organización racional del Estado y de las relaciones sociales, como la desarrollada por Hegel (1975), Weber (1977) y la escuela funcionalista, por ejemplo; y aquella que denuncia la función ideológica y conservadora de la misma, como Marx y Engels (1993), Lúkacs (1979) y Horkheimer (2002), o algunos autores vinculados al análisis institucional, como Lourau (1975) y Lapassade (1977), entre otros.

Lapassade (1977) en particular, hace un extenso análisis de la cuestión burocrática, considerando los principales autores que trabajaron esta cuestión. Se establece aquí un nexo entre Hegel (1975) y Weber (1977), a través de la definición de este último de la burocracia como empresa de racionalización integral de la producción y de la vida social que tiende a una racionalidad integral de los sistemas administrativos y políticos. Arendt (1967) afirma, de acuerdo con esta definición weberiana, que el buen burócrata debe ser reflexivo y extender al límite su inteligencia y su capacidad de cálculo.

Mayo (1988) apuntan a encontrar un método que facilite el funcionamiento de los grupos, principalmente dentro de las empresas, cuyo propósito último sea modernizar, agilizar la burocracia. Merton (1964) - desde un punto de vista similar al de Mayo-, considera que las fallas de una organización se deben a sus integrantes, no a la propia organización en sí.

Marx y Engels (1982) muestran el carácter negativo del fenómeno burocrático. La burocracia representa aquí un orden simplemente formal que intenta ocultar conflictos y antagonismos de clase y conservar el orden social vigente.

Lenin (1981) vislumbró el peligro que significaba el aparato burocrático estatal para el desarrollo económico y social de la recién constituida Unión Soviética, el cual atribuyó a la herencia de la máquina estatal del régimen anterior y sus funcionarios. En Trotski (1973) esta crítica se acentúa y se dirige al estalinismo, considerada una clase parasitaria.
Dentro de los autores marxistas, resulta interesante rescatar el análisis althusseriano sobre la función ideológica de los aparatos del Estado, tanto de aquellos que tienen una función declaradamente represiva (la policía, por ejemplo), como de los que disimulan su función de reproducción de determinadas estructuras sociales (como la educación; Althusser, 1974).

Lejos de promover un proceso de extinción progresivo del Estado como indicaba la teleología marxiana, la creación y consolidación de los estados socialistas aumentó y fortaleció esas estructuras burocráticas, lo cual llevó a paralizar y vaciar de contenido a procesos sociales que originalmente tenían una tremenda potencialidad y vitalidad. Una lectura simplista y grosera de relación directa y unidireccional entre estructuras económicas y superestructuras culturales y sociales, así como la noción reduccionista según la cual el sujeto es un mero producto de las relaciones sociales de producción, contribuyeron en ese sentido.

La negación de la noción de subjetividad individual se expresó de forma clara en las dificultades que el derecho penal soviético - principalmente durante el estalinismo-experimentó en el proceso de comprender la existencia de conductas criminales en la Unión Soviética. Desaparecidas en teoría las condiciones sociales que determinaban y explicaban los comportamientos socialmente desviados, fue necesario establecer la difusa figura de "enemigo del pueblo" (basada en la idea de la existencia de elementos remanescentes burgueses en la sociedad socialista), a fin de punir ese tipo de conductas. Curiosamente, aparece implícito aquí un presupuesto de base idealista: deducir la realidad a partir de una idea, al procurar que la primera "encaje" en la segunda.

La psicología soviética padeció de las mismas limitaciones político-epistemológicas. La suposición, según la cual una sociedad sana produciría de forma directa individuos sanos, impidió el desarrollo de la psicología clínica, reducida en general a las limitadas posibilidades que ofrecía la teoría reflexológica (González-Rey, 2007).

Para Bourdieu (1997), la burocracia en este sistema político exigía "una conformidad con la norma, no un juicio moral" (p. 115), al operar como un aparato al servicio de la inhabilitación ética de los individuos. Bourdieu distingue entre capitales económicos, sociales, culturales y sociales, cuya apropiación y acumulación permite ciertas formas de circulación social y poder, lo cual determina también conductas e identidades. 
Los conceptos de instituido e instituyente ${ }^{1}$ son útiles para entender este tipo de fenómenos de cristalización y anquilosamiento de procesos colectivos, los cuales acontecen tanto a nivel macro-social como institucional o grupal, de manera que se suceden momentos de apertura de nuevos procesos y despliegue de potencialidades subjetivas con momentos posteriores en los que estos se estabilizan, consolidan y crean estructuras, prácticas y discursos que sirven a la mera reproducción de lo mismo.

De esta forma, las prácticas burocráticas vinculadas a esos instituidos consiguen crear un distanciamiento entre la praxis de los sujetos que las encarnan con relación a los efectos de las mismas. Se puede hablar aquí de reificación en el sentido que le otorgó Lukacs (1979), en tanto aquello que transforma a los seres humanos en res, que vacía su existencia de sentido.

Arendt (1967) ofrece un ejemplo contundente al respecto cuando analiza el funcionamiento de la maquinaria de exterminio nazi, y va más allá de las decisiones y planificación de los jerarcas del régimen hitleriano e incluye a los pequeños burócratas que permitían que esa maquinaria funcionara. Estos realizaban, por ejemplo, la lista de los prisioneros a ser ejecutados, o bien vigilaban que la provisión de gas de las cámaras de exterminio no se agotase. Esas prácticas son definidas por esta autora como la banalidad del mal, banales en tanto distantes de cualquier reflexión sobre sus consecuencias. Bauman (2007) amplía esta consideración, al afirmar que lo verdaderamente insoportable de estos procesos no es situarse en el lugar de posible víctima de los mismos, sino de ocupar el lugar de victimario, como producto de dinámicas sociales y políticas particulares.

Sartre (2006) dedica también un exhaustivo análisis a la cuestión de la burocracia, definida como una pirámide en cuya cúspide está el Estado. El propósito último de la misma es impedir la libertad de los sujetos sobre los cuales opera.

En Castoriadis (1986), la noción de burocracia está asociada a una de las formas en que la dimensión imaginaria se presenta, de manera que lo imaginario no se ubica aquí como una instancia pre-simbólica o asociada a lo patológico. Por el contrario, tiene una

1 Lo instituido, resultado de la acción instituyente, representa una tendencia a conservar y reproducir de la misma manera determinados procesos grupales y funcionamientos institucionales. Lo instituyente representa las acciones innovadoras que apuntan a producir una mudanza en lo instituido (Baremblitt, 1992). función de organización de la realidad y de producción de sentidos.

Bleger (1966), por otra parte, destaca que la burocracia en las organizaciones se respalda en tipos particulares de personalidad y de relación interpersonal y grupal.

La película La vida de los otros (Henckel von Donnersmarck, 2006), cuyo análisis constituye el objetivo de este texto, retrata de forma precisa la relación entre las prácticas burocráticas y las formas de producción de subjetividad propias de la ex Alemania Oriental a través del contrapunto que establece entre la vida del actor principal, un espía de los servicios de informaciones del Estado (Stasi), y la de un grupo de artistas a los que debe espiar por indicación de un burócrata del régimen. La forma en que esta relación repercute en los protagonistas muestra los límites y posibilidades que este contexto social impone a cada uno de ellos en términos de construcción de nuevos sentidos en torno a sus acciones y pensamientos.

\section{Referencias teóricas}

González-Rey (2003; 2004; 2007) reintroduce la cuestión de la subjetividad desde una perspectiva dialéctica que se inscribe en el marco de la psicología histórico-cultural, de clara influencia vigotskiana. Esta perspectiva dialéctica apunta a superar las dicotomías entre lo interno y lo externo, entre la dimensión individual y social, dicotomías estas que marcaron la historia de la psicología y de las ciencias humanas y sociales en general. Esta noción de subjetividad se configura como un sistema complejo, el cual se produce de forma simultánea en el nivel social e individual, y que se expresa también en la historia individual del sujeto.

La noción de subjetividad fue tradicionalmente desconsiderada por las ciencias sociales modernas. Desde la psicología, en particular, el paradigma positivista dominante asimiló lo subjetivo al error, a una dimensión íntima del sujeto imposible de medir o analizar y la cual debía ser desconsiderada en nombre de la objetividad. Posteriormente, el denominado giro lingüístico o narrativo subsume toda realidad a una dimensión discursiva, en la que el sujeto está preso en "juegos de lenguaje" que lo aprisionan, negando su dimensión intencional y creativa.

El desarrollo teórico de González-Rey avanza sobre la definición de sentido de Vigotsky, expresada en Pensamiento y Lenguaje (1978), a través de la noción de sentido subjetivo, definido como "la unidad 
inseparable de los procesos simbólicos y las emociones en un mismo sistema, en el cual la presencia de uno de esos elementos evoca al otro, sin que sea absorbido por el otro." (González-Rey, 2003, p. 127). Estos elementos de sentido se integran en configuraciones subjetivas más amplias y complejas.

El concepto de subjetividad así planteado implica necesariamente una concepción determinada de sujeto. Para González-Rey, el sujeto es "...un individuo consciente, intencional, actual e interactivo" (2003, p. 236), que "está constituido por configuraciones subjetivas que no concientiza" (p. 50). Al mismo tiempo, el sujeto produce, de manera consciente, proyectos y representaciones que tienen capacidad de subjetivación y originan significados y sentidos, los cuales están más allá de su conciencia e intención original. Cabe aquí destacar el lugar de la emoción como condición permanente del mismo.

La noción de subjetividad social, útil a los fines de este trabajo, pretende integrar varios elementos sociales, tales como las representaciones sociales, los mitos, el sentido común, los discursos y los comportamientos sociales, entre otras dimensiones, que expresan procesos y formas de organización subjetivas constituyentes y constituidas por el sujeto individual. En la historia particular de un sujeto se expresan, de forma parcial y singular, elementos del tejido social en que interactúa.

La manifestación diferenciada del sujeto en los espacios sociales que integra "está subjetivamente constituida por sentidos subjetivos procedentes de sus experiencias actuales y anteriores dentro de otros espacios sociales" (González-Rey, 2003, p. 195), y que contribuyen a formar su identidad, entendida no como formación intrapsíquica, sino como el sentido de reconocimiento que el sujeto experimenta en el transcurso de sus acciones desarrolladas por un sujeto concreto en condiciones sociales específicas.

Estas experiencias se inscriben en las necesidades actuales del sujeto, que a la vez mantienen un carácter histórico y que representan "[...] complejas síntesis de la historia social del sujeto" (GonzálezRey, 2004, p. 44).

El sujeto define nuevas alternativas de acción en su práctica social que pueden entrar en conflicto con su identidad y sus sistemas de sentido históricamente constituidos. De esta forma, tiende a superar los límites estrechos que la subjetividad social dominante coloca (González-Rey, 2007).

De esta forma, "el ser sujeto implica una posición crítica, la toma de decisiones en el curso de una actividad, la defensa de un punto de vista y asumir su lugar en el curso de esa actividad" (González-Rey, 2007, p. 146).

Las instituciones tienden a limitar la expresión singular de los sujetos. Esto al producir un distanciamiento entre el sentido y los motivos de sus prácticas y el significado de las mismas, de manera que se muestran así tendencias autoritarias y domesticadoras que "no toleran las manifestaciones altamente personalizadas" (González-Rey, 2004, p. 238). Los momentos de cambio institucionales y sociales permiten que el sujeto reconfigure esta relación, y demanda que él mismo produzca nuevos sentidos frente a esta situación, la cual puede constituirse en una amenaza para su salud mental y llevar a una crisis subjetiva.

En relación con la cuestión específica de la burocracia, es posible pensar una aproximación a este marco teórico a partir de su definición como un fenómeno de carácter ideológico que genera un desconocimiento "provocado por la represión social del sentido" (Lapassade, 1977, p.32). Esta imposibilidad de generar nuevos sentidos y significados define la función conservadora y alienante de la burocracia. El término alienación debe ser entendido como la imposibilidad de un sujeto o grupo de reflexionar y colocar en cuestión su relación con su realidad cotidiana.

Por esto, para Lapassade la burocracia es, ante todo, una cuestión política, un cierto tipo de relación de poder "que atraviesa toda la vida social, desde las relaciones de producción hasta el placer", constituyéndose así en "la organización de la separación, reguladora del comportamiento social" (Lapassade, 1977, citado por Guirado, 1987, p. 34).

\section{Descripción de la película}

La película alemana La vida de los otros (Henckel von Donnersmarck, 2006) transcurre en la ex Alemania Oriental durante la época previa al colapso del régimen comunista. El protagonista principal, el capitán Gerd Wiesler (Ulrich Mühe), es un eficiente y disciplinado integrante del servicio de inteligencia del Estado (Stasi), agencia encargada de la vigilancia interna de los ciudadanos, principalmente de su fidelidad y adhesión al partido comunista y al gobierno. La función específica de este sujeto es implementar escuchas y seguimientos a los sospechosos de ser opositores al régimen, así como formar a los nuevos integrantes de la organización en estas técnicas. La forma impersonal y distante en que este pequeño burócrata desempeña su función aparece en la película muy bien retratada. 
Su superior inmediato, presentado como un ambicioso e inmoral funcionario, maneja un discurso de adhesión al régimen y sus principios, mas que opera apenas al servicio de su ambición de poder y es utilizado de forma funcional a ese interés.

Una pareja conformada por el escritor Georg Dreyman (interpretado por Sebastain Koch) y la actriz de teatro Christa-Maria Sieland (Martina Gedenk), son sospechosos de actividades opositoras y seguidos por el protagonista. Este monta un sistema de escuchas a través de micrófonos instalados en el departamento de los investigados.

La trama de la película exhibe un doble proceso: el de los artistas, que se desengañan progresivamente con el sistema, y el del espía, cuya fidelidad institucional comienza a agrietarse a medida que percibe la distancia entre los propósitos declarados de la institución, el gobierno que integra y su real funcionamiento. La película deja entrever que este contrapunto tiene una relación directa con la vida íntima del sujeto, de una enorme miseria personal y soledad.

Enfrentado a la decisión de cumplir con la misión de acusar a los investigados o defender el mandato de su conciencia - que indica la inocencia de los mismos-, elige el segundo camino lo que lo lleva a exponerse frente a sus jefes y a colocar en riesgo su carrera dentro de la institución.

En la escena final, esta trama de intrigas y dobles lealtades lleva a la muerte de una de las artistas, sofocada por estos dispositivos de control y por su propia conciencia. Fue presionada, primero para convertirse en la amante del burócrata que había ordenado su seguimiento, y más tarde para traicionar y delatar a su compañero. Este último salva su vida merced a la intervención del protagonista, quien oculta la máquina de escribir con la cual había sido escrito un artículo contra el régimen.

Una vez se da la caída del muro de Berlín y el fin de la Alemania Oriental, el ahora ex espía aparece trabajando como cartero. En la última escena de la película se encuentra con el reconocimiento tardío de su acción, realizada a través de la dedicatoria de un libro de su anterior perseguido. Aun así, esta dedicatoria se dirige a él de forma anónima, apenas por su número de identificación institucional, ya que su identidad permaneció oculta en todo momento.

Este cierre muestra de forma cruda el carácter gris de la existencia del protagonista, su subjetividad privada de sentido que se expresa en una profunda alienación, en la cual aun el único acto que pareció contradecir ese carácter permaneció para él privado de sentido subjetivo y trascendencia. De alguna forma, la banalidad del bien.

\section{Análisis de la película}

La película muestra los procesos de crisis que dos de los protagonistas atraviesan en relación con sus sistemas de creencias, y el vínculo con su entorno social y la pertenencia institucional. De los dos, el escritor es el que tiene condiciones subjetivas para procesar estos episodios y otorgarle nuevos sentidos y significados a los mismos. Los grupos a los que pertenece, y en los que circula, refieren a una subjetividad social no atrapada por las redes de poder y sometimiento que la burocracia del Estado impone. Por ese motivo, él y sus colegas son mirados con sospecha por los agentes del régimen. La actividad artística en sí supone una dimensión de creatividad, de libre expresión del sujeto que suele ser vista con desconfianza por los sistemas totalitarios de gobierno, tanto por lo que significan para los protagonistas, como por lo que pueden generar en el público.

La creatividad, según González-Rey (2007), expresa la capacidad humana para subvertir lo dado y representa una posibilidad de producción de sentidos subjetivos diferenciados, lo cual puede expresarse en una práctica social transformadora.

El espía, protagonista principal de la trama, no goza de las mismas condiciones individuales y sociales. En este sentido, la película muestra un contraste apropiado entre la inexpresividad enorme de este personaje, y la soltura y el desparpajo de los actores, como si esa diferente capacidad de expresar los sentimientos mostrase también los límites de realización, de acción y de expresión social de cada sujeto.

Esta pobreza subjetiva muestra también su rostro en la vida íntima del espía, quien vive solo en un pequeño apartamento desprovisto casi de objetos personales. Su sexualidad se limita a encuentros ocasionales con prostitutas, despersonalizados y carentes de afecto, de alguna forma también burocráticos y que tienen como fondo la tonalidad social "algo gris y uniforme de la sociabilidad pública” (Bourdieu, 1997, p. 31).

Por estos motivos, las acciones que emprende en defensa de las personas a las que debía perseguir significan un conflicto entre los sentidos derivados de sus acciones y los vinculados históricamente a su organización subjetiva, de carácter más estructural. Este proceso personal lo sitúa en crisis con respecto a su identidad y pertenencia institucional, pero no 
le permite producir nuevos sentidos y significados, lo que constituye una condición patológica, en tanto generadora de sufrimiento psíquico. No es la experiencia en sí lo que le provoca ese quiebre identitario, sino su incapacidad de asimilarla y encuadrarla, producto del orden social que habita y el espacio institucional al que pertenece.

Para González-Rey (2007), en la medida en que la persona "pierde participación en la producción de sentidos subjetivos asociados a diferentes áreas de su vida, queda a merced de los otros" (González-Rey, 2007, p. 162), de forma que ese otro puede ser una persona, un grupo o una institución.

No obstante, esta tensión subjetiva conmueve y dificulta su trabajo. Lo aparta de un cierto "deber ser" burocrático, en el cual,

Lo que no se debe hacer es permitir que nada los desvíe del camino correcto de la racionalidad sabia e inflexiblemente centrada en la tarea en cuestión: ni la compasión, ni la simpatía ni la antipatía por los objetos ni las lealtades o los compromisos que no sean con la tarea y la lealtad debida a los compañeros burócratas (Arendt, 1967, p. 85).

Según González-Rey (2004), la subjetividad "aparta el deber ser de su relación con lo externo, con lo que está fuera, que fue el principio universal usado para legitimar la moral, el derecho, la política y todas las formas institucionales de conciencia social" (González-Rey, 2004, p. 54). La manifestación subjetiva del protagonista lo aparta de un deber ser y le devuelve fugazmente su condición de sujeto, pero no se inscribe en un proceso de transformación de su configuración subjetiva de carácter más amplio y estructural. Por este motivo, retorna a las mismas prácticas burocráticas que lo agobian, desde una distancia y sufrimiento mayores.

Se quiebra así la barrera que le permitía despersonalizarse, tomar distancia de sus actos. En la descripción que Arendt (1967) realiza del criminal nazi Eichmann, con motivo de su juzgamiento en Israel, destaca el hecho de que este manifestaba actuar, "motivado por lealtad de servicio", ya que lo malo sería desobedecer las órdenes, considerando que, "su único móvil fue hacer un trabajo bien hecho" (Arendt, 1967, p. 82). De esta manera, según Arendt, se expropia la sensibilidad y la responsabilidad del sujeto en relación con sus actos.

Conforme con Lapassade (1977), la represión social del sentido que la burocracia institucional impone operaría aquí estableciendo un límite y obturando el potencial del sujeto para establecer un nuevo sentido subjetivo a sus acciones.

En los denominados socialismos reales, los métodos de control social avanzan sobre la intimidad de las personas, de modo que el sujeto "aparece más como sujeto de la acción, integrado a un tejido colectivo que impide su singularidad, que como sujeto de decisión, con lo cual adquiere atributos objetales" (González-Rey, 2003, p. 114).

En este sentido, Meszáros (2006) destaca, desde Marx, que la destrucción del Estado capitalista y la eliminación de sus restricciones jurídicas no resuelven la alienación subjetiva que el capitalismo produce, destacando el peligro de seguir fijando a la sociedad como una abstracción frente al individuo. De esta forma, la autoconciencia del individuo permanece alienada, distante de su realización como ser social.

Paradójicamente, la crítica que Marx y Engels (1993) le dirigen a la sociedad burguesa, en el sentido de separar al ciudadano público del individuo privado y alejar al hombre de su "ser comunitario", se resuelve en estos sistemas políticos a través del recorte de las libertades individuales y de formas amplias de integración comunitaria, en nombre de la pertenencia y obediencia al Estado. De esta forma, lo político pasa a ser un contenido formal, moralmente vacío, más que una expresión auténtica del sujeto (González-Rey, 2007).

Una experiencia sobre la cual no se puede producir sentidos dice mucho en relación al sujeto que la protagoniza, pero también expresa elementos de su subjetividad social, de las formas de relación social y de la cultura que integra y por la cual circula. En este sentido, se puede afirmar que las sociedades que limitan estos espacios de simbolización y producción subjetiva tienen un potencial patogénico.

El orden simbólico que permite el funcionamiento de estos mecanismos se asienta en la imposición de estructuras cognitivas y de significado que gozan de consistencia y resistencia por el hecho de ser "por lo menos en apariencia, coherentes y sistemáticas y de estar objetivamente en consonancia con las estructuras objetivas del mundo social" (Bourdieu, 1997, p. 119).

En el capitalismo, el sistema actual de alienación y control que se expresa fundamentalmente en relación al consumo como imperativo de pertenencia e integración social, impide a los sujetos la construcción de sentidos y significados en torno al carácter real de esta exigencia, produciendo así manifestaciones 
patológicas que mantienen cierta relación de significación con la cuestión del consumo en general, pero sin llegar a constituirse en una reflexión que permita colocar en cuestión parámetros identitarios y prácticas vinculadas al mismo, sobre las cuales no se produce sentido.

Cabe pensar aquí una relación posible entre el fenómeno contemporáneo de las adicciones y los denominados trastornos de la alimentación, como las bulimias y las anorexias. La cuestión del consumo atraviesa estas manifestaciones patológicas, revelando así características de la subjetividad social y la cultura de nuestra época.

Para González-Rey (2007), actualmente el consumo pasó a ocupar un aspecto central en la vida de las personas, a partir del establecimiento de una lógica consumo-dinero que "aliena a la persona en relación a sus vínculos y procesos de relación (González-Rey, 2007, p. 172).

Bourdieu (1997) establece una distinción apropiada entre el funcionamiento de los dos sistemas sociales. En el socialismo real, el capital económico estaría fuera de juego a la hora de determinar jerarquías y formas de circulación social, de manera que la distribución de poder y bienes está vinculada a la apropiación y acumulación de capital político. Esta acumulación desigual es más injusta en la medida en que los aparatos burocráticos y represivos excluyen a sectores importantes de la población de los sistemas de poder y decisión.

\section{Conclusiones}

Sartre (2006) afirmó que el escape a la serialidad del poder, a la alienación, pasa por la posibilidad de recuperar la soberanía sobre los propios actos. La pra$x$ is de los sujetos, al mismo tiempo en que permite su alienación, abre las puertas para su libertad.

Esta praxis libertaria debe inscribirse en procesos colectivos de transformación para que puedan expresarse en cambios sociales e institucionales concretos. Estos procesos no responden a determinaciones pre-concebidas, ni obedecen a leyes históricas, sino que se producen en la articulación entre factores sociales y económicos estructurales, así como la cultura y las formas de relación propias de cada época y sociedad, las cuales constituyen también formas de subjetividad social. Los sujetos concretos actúan en estos procesos al producir nuevos sentidos y significados que escapan a la capacidad de racionalización y simbolización de los mismos.
El pensamiento conservador se ha apropiado de la noción de libertad en la historia reciente. Cabe aquí marcar una diferencia fundamental: la libertad a la que esta operación ideológica alude es la del individuo, supuesto dueño absoluto de sus actos y cuyo vínculo con lo social es de pura conflictividad, en tanto amenaza a esta individualidad; el concepto de subjetividad aquí empleado refiere a la praxis de los sujetos en el seno de su contexto social productor y producto de esta praxis.

No se trata entonces de negar o invalidar los procesos de cambio social en nombre de un pesimismo vinculado a la suposición de su inevitable debacle, paralización y distanciamiento para con sus propósitos iniciales (este tipo de afirmación se aproximaría peligrosamente a la conservadora noción posmoderna del fin de la historia), sino de colocar en cuestión los determinismos que contribuyeron a que estos procesos no mantuvieran su potencial transformador a lo largo del tiempo, empobreciéndose paulatinamente hasta entrar en puntos de contradicción con los propios principios que los generaron.

En este sentido, recuperar la noción de sujeto supone también una afirmación de carácter político, necesaria para los tiempos que corren.

\section{Referencias}

Althusser, L. (1974). Ideologia e aparelhos ideológicos do Estado. Lisboa: Ed. Lisboa.

Arendt. H. (1967). Eichmann in Jerusalém. A report on the banality of evil. New York: Penguin Books.

Baremblitt, G. (1992). Compendio de análise Institucional. Rio de Janeiro: Rosa dos Tempos.

Bauman, Z. (2007). Miedo líquido. La sociedad contemporánea y sus temores. Barcelona: Paidós.

Bleger, J. (1966). Psicohigiene y psicología institucional. Buenos Aires: Paidós.

Bourdieu, P. (1997). Razones prácticas. Sobre la teoría de la acción. Barcelona: Ed. Anagrama.

Castoriadis, C. (1986). A instituição imaginária da sociedade. São Paulo: Paz e Terra.

Foucault, M. (1978) La microfísica del poder. Madrid: Ed. La Piqueta.

González-Rey, F. (2003). Sujeito e subjetividade. São Paulo: Pioneira Thomson Learning.

González-Rey, F. (2004). O social na psicologia e a psicologia no social. A emergência do sujeito. Petrópolis: Vozes. 
González-Rey, F. (2007). Psicoterapia, subjetividade e pós-modernidade. San Pablo: Thomson.

Guirado, M. (1987). Psicología Institucional. San Pablo: EPU.

Hegel, G. (1975). Filosofía del derecho. México: Universidad Nacional Autónoma México.

Henckel von Donnersmarck, F. (Dir.). (2006). Das leben der anderen [Película]. München: Wiedemann \& Berg Filmproduktion.

Horkheimer, M. (2002). Crítica de la razón instrumental. Madrid: Trotta.

Lapassade, G. (1977). Grupos, organizações e instituições. Rio de Janeiro: Sindicato Nacional de Editores de Livros.

Lenin, V. (1981). Obras Completas. Moscú: Progreso.

Lourau, R. (1975). A análise institucional. Petrópolis: Ed. Vozes.

Lúkacs, G. (1979). Ontología del ser social. Buenos Aires: Nueva Visión.

Marx, K. y Engels, F. (1982). O capital: crítica da economia política. Rio de Janeiro: Civilização Brasileira.
Marx, K. y Engels, F. (1993) A Ideología alemã. São Paulo: Ed. São Paulo.

Mayo, E. (1988). The social problems of an industrial civilization. New Hampshire: Company Publishers.

Merton, R. (1964). Teoría y estructuras sociales. México: FCE.

Meszáros, I. (2006). A teoria da alienação. São Paulo: Boitempo.

Sartre, J. (2006). Crítica de la razón dialéctica. Buenos Aires: Losada.

Trotski, L. (1973). La revolución rusa. Buenos Aires: FC Editor.

Vygotsky, L.S. (1934/1978). Pensamiento y Lenguaje. Madrid: Paidós.

Weber, M. (1977). Economía y sociedad. México: Fondo de Cultura Económica. 